\title{
Removal of Fluoride from Water by Adsorption onto Fired Clay Pots: Kinetics and Equilibrium Studies
}

\author{
G. P. Kofa, ${ }^{1,2}$ V. H. Gomdje, ${ }^{2}$ C. Telegang, ${ }^{1}$ and S. Ndi Koungou ${ }^{1}$ \\ ${ }^{1}$ Water Treatment and Filtration Research (Chem. Eng.) Group, Department of Process Engineering, ENSAI, \\ University of Ngaoundere, P.O. Box 455, Ngaoundere, Cameroon \\ ${ }^{2}$ Higher Institute of Sahel (ISS), University of Maroua, Maroua, Cameroon \\ Correspondence should be addressed to G. P. Kofa; guikofa@yahoo.fr
}

Received 15 February 2017; Revised 24 April 2017; Accepted 29 May 2017; Published 4 July 2017

Academic Editor: Christos Kordulis

Copyright (C) 2017 G. P. Kofa et al. This is an open access article distributed under the Creative Commons Attribution License, which permits unrestricted use, distribution, and reproduction in any medium, provided the original work is properly cited.

\begin{abstract}
Excessive fluoride in potable water is a serious health problem in rural areas of many developing countries. Hence, there is a need to find a simple and cost-effective method for water defluoridation in such areas. In the northern part of Cameroon, clay pots are used for cooking food and water storage. The firing of these pots consists of intensive burning using fire wood. They were tested as a potential adsorbent for removing excess fluoride from water. Experiments were carried out in a jar test at room temperature $\left(25 \pm 2^{\circ} \mathrm{C}\right)$. Effects of contact time (0-90 min), $\mathrm{pH}(4,5,7,8$, and 9), stirring speed $(60,90,120$, and $200 \mathrm{rpm})$, and ionic strength $(0-1000 \mathrm{mg} / \mathrm{L})$ were investigated. Results showed that equilibrium was attained in $10 \mathrm{~min}$ whatever the $\mathrm{pH}$. Pseudo-second-order and pore diffusion models described well the adsorption process. The highest amount of fluoride adsorbed (1.6 mg/g) was obtained at $\mathrm{pH}$ 4-5 and the optimum stirring speed is $120 \mathrm{rpm}$. Ionic strength has a significant effect on fluoride adsorption.
\end{abstract}

\section{Introduction}

Fluoride ion exists in natural waters and it is an essential micronutrient in humans in preventing dental caries and in facilitating the mineralization of hard tissues if taken at a recommended range of concentration. Higher level of fluoride in groundwater is a worldwide problem [1-3]. The World Health Organization (WHO) has set a guideline of $1.5 \mathrm{mg} / \mathrm{L}$ for fluoride in potable water [4]. Concentration higher than this value can lead to fluorosis (dental and/or skeletal) and several types of neurological damage in severe cases [5]. Many methods have been developed for fluoride removal from water such as adsorption [6], ion exchange [7], membrane processes such as reverse osmosis and nanofiltration $[8,9]$, electrodialysis $[10,11]$, and precipitation [12]. Among these methods, adsorption is a widely used method for defluoridation which depends on ions (adsorbate) in fluid diffusing to the surface of a solid (adsorbent) when they are bound to the solid surface or are held there by weak intermolecular forces [13]. Adsorption is recognized as the most efficient, promising, and widely used fundamental approach in water and wastewater treatment processes [14].
Different adsorbents such as activated alumina [15], bleaching earth [16], iron oxide [17], activated titanium rich bauxite [18], activated carbon [19], red mud [20], and clay [21, 22] were tested to find out efficient and economically viable defluoridating ones. Among these adsorbents, clay and clay minerals are naturally abundant, renewable, and environmentally sustainable [23-25]. They are considered robust adsorbents [24] due to their low cost, sorption properties, and ion exchange potential. In recent years, considerable amount of work has been done on activation of clay and clay minerals to improve the adsorption capacity and hence removal efficiency [26, 27]. Chemical and physical activation methods are commonly used. However chemical treatment has not always proven to be effective. For example, Ma et al. [28] reported equilibrium fluoride adsorption capacity by granular acid treatment of bentonite of just $0.07 \mathrm{mg} / \mathrm{g}$. That is why some researchers turn to heat treatment which can also increase ions adsorption capacity in clay $[29,30]$.

Clay pot is made of a mixture of different types of natural clays. The process consists of mixing the different clay fractions, forming the pot, and burning under an intensive wood fire (around $300^{\circ} \mathrm{C}$ ) where they get cooked. During 


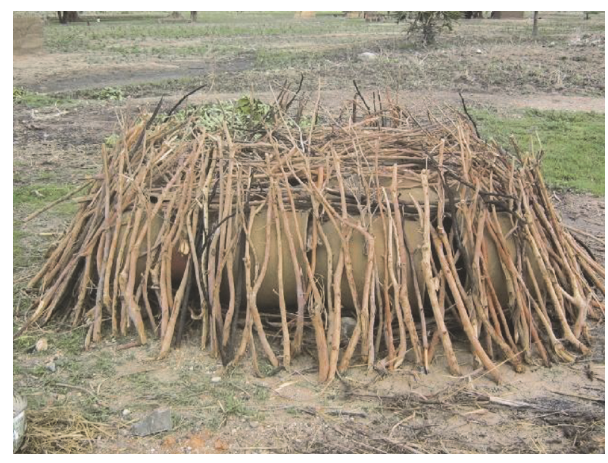

FIGURE 1: Firing process of clay pots.

the firing process (cooking phase) some of them get broken. These broken pots are not useful for water storage but could be used as an adsorbent, because they are primary heated clays. The main objective of this investigation is to study the removal efficiency of fired clay pots powder as a potential adsorbent for fluoride removal under different physicochemical conditions.

\section{Materials and Methods}

2.1. Materials. Clay pots were collected from Kouladje, a village in the northern part of Cameroon. The firing of these pots consists of its intensive burning using fire wood (Figure 1). The clay powder was obtained after crushing and sieving a clay pot with standardized stainless sieves and the fraction less than $100 \mu \mathrm{m}$ was collected.

All other reagents used in the present study were of analytical grade. A stock solution of fluoride $1000 \mathrm{mg} / \mathrm{L}$ was prepared by dissolving appropriate quantity of sodium fluoride (Sigma-Aldrich, USA) in distilled water.

2.2. Characterization of Adsorbent. The surface morphology of the fired clay powder was examined using scanning electron microscopy (Hitachi S-3000H, Japan) microscope with an accelerating voltage of $15 \mathrm{kV}$. EDAX was also performed on the same device. The specimens were prepared using carbon tape.

2.3. Batch Adsorption Studies. Adsorption experiments were carried out on a jar test (batch mode) at different $\mathrm{pH}(4,5$, $7,8$, and 9$)$ ionic strengths $(0-1000 \mathrm{mg} / \mathrm{L})$ and stirring speed $(60,90,120$, and $200 \mathrm{rpm})$. In a typical run, beakers $(1 \mathrm{~L})$ were filled with $500 \mathrm{~mL}$ of fluoride solution of predetermined concentration, with $\mathrm{pH}$ adjusted to the desired value with $0.1 \mathrm{M} \mathrm{NaOH}$ or $0.1 \mathrm{M} \mathrm{HCl}$ solution. The ionic strength of the solution was also adjusted by adding $\mathrm{KNO}_{3}$ solution. A predetermined amount of adsorbent was added to the beaker and the resulting suspension was stirred at a fixed speed. After a given time, the stirring stopped, the suspension was centrifuged (BIOFUGE Heraeus, Germany) at $950 \mathrm{~g}$, and the supernatant was filtered on a Minisart X50 (Prolabo, France) membrane filter of porosity $0.1 \mu \mathrm{m}$. The residual fluoride concentration in the aqueous solution was measured by
TABLE 1: Elemental compositions of Kouladje fired clays obtained by EDAX.

\begin{tabular}{lcc}
\hline Elements & Weight $(\%)$ & Atomic $(\%)$ \\
\hline Oxygen $(\mathrm{O})$ & 40.26 & 55.02 \\
Sodium $(\mathrm{Na})$ & 0.20 & 0.19 \\
Magnesium $(\mathrm{Mg})$ & 0.25 & 0.23 \\
Aluminium $(\mathrm{Al})$ & 3.48 & 2.82 \\
Silicon $(\mathrm{Si})$ & 51.30 & 39.93 \\
Potassium $(\mathrm{K})$ & 0.27 & 0.15 \\
Iron $(\mathrm{Fe})$ & 4.23 & 1.66 \\
\hline
\end{tabular}

means of a multiparameter analyser (Consort 869, Belgium) equipped with fluoride ion specific electrode (ELITE 201, England).

Isotherm experiments were carried out at $\mathrm{pH}=4$, by varying fluoride concentration ranging from 1 to $64 \mathrm{mg} / \mathrm{L}$. The amount of fluoride adsorbed $(q)$ was calculated as the change in the aqueous phase concentration from initial value according to

$$
q=\frac{\left(C_{0}-C\right)}{m} \times V
$$

where $C_{0}$ and $C(\mathrm{mg} / \mathrm{L})$ are the initial fluoride concentration and at contact time $t,(\mathrm{~min}), V(\mathrm{~L})$ is the volume of solution, and $m(\mathrm{mg})$ is the amount of adsorbent added.

\section{Results and Discussion}

3.1. Morphological and Elemental Composition of Fired Clay. Clay morphology at different magnification is presented on Figure 2. It is observed from this figure that the morphology of the fired clay is compact with interlayers which are favorable for adsorption phenomena. This compactness of the morphology is due to the effect of the temperature applied on these clays during the firing process of pots. The EDAX spectrum of Figure 3 showed the presence of $\mathrm{Na}, \mathrm{Mg}, \mathrm{Al}, \mathrm{Si}$, $\mathrm{Fe}, \mathrm{K}$, and $\mathrm{O}$. Clay is mainly composed of silica as shown in Table 1 and can be explained by the fact that the extraction zone is composed of the sand-clay types [31].

3.2. Kinetic Study. The kinetic study was carried out in an agitated vessel as described earlier by changing the various operating conditions.

3.2.1. Effects of $p H$. Figure 4 shows a comparison of the amount of fluoride adsorbed at different $\mathrm{pH}$ as a function of contact time. The examination of these kinetic curves reveals a rapid adsorption to attain the equilibrium adsorption. In all the $\mathrm{pH}$ used, two phases were observed: (a) the first phase, where the adsorption is rapid and appeared within the $10 \mathrm{~min}$ contact time; (b) the second phase, where the amount of fluoride adsorbed remained constant after $10 \mathrm{~min}$ of contact time, implying that equilibrium was reached. In general, the fast adsorption could be attributed to a surface reaction process. It is also shown in Figure 4 that the adsorption density decreases with the increase of $\mathrm{pH}$. This can be 

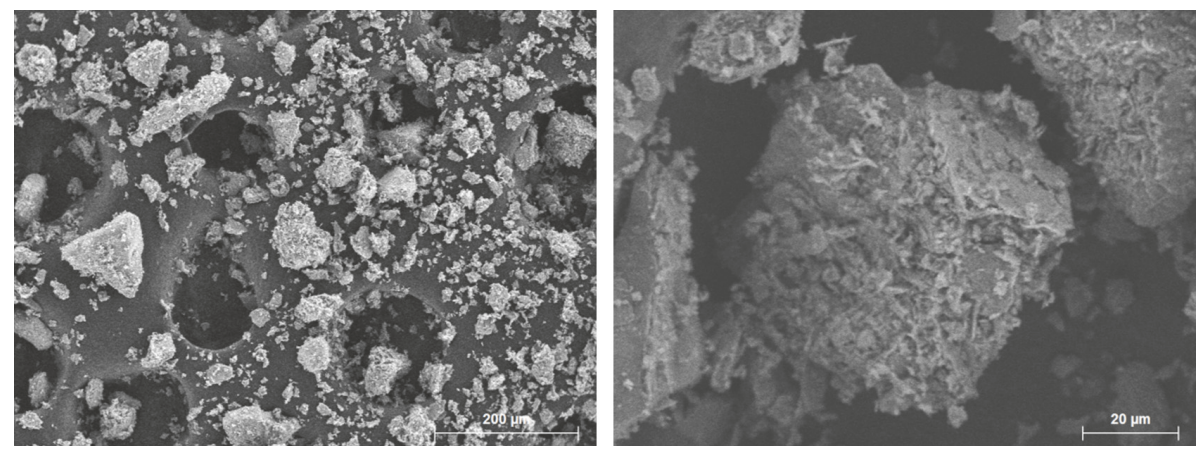

FIGURE 2: Electron microscopy image of clay pot powder at different magnification.

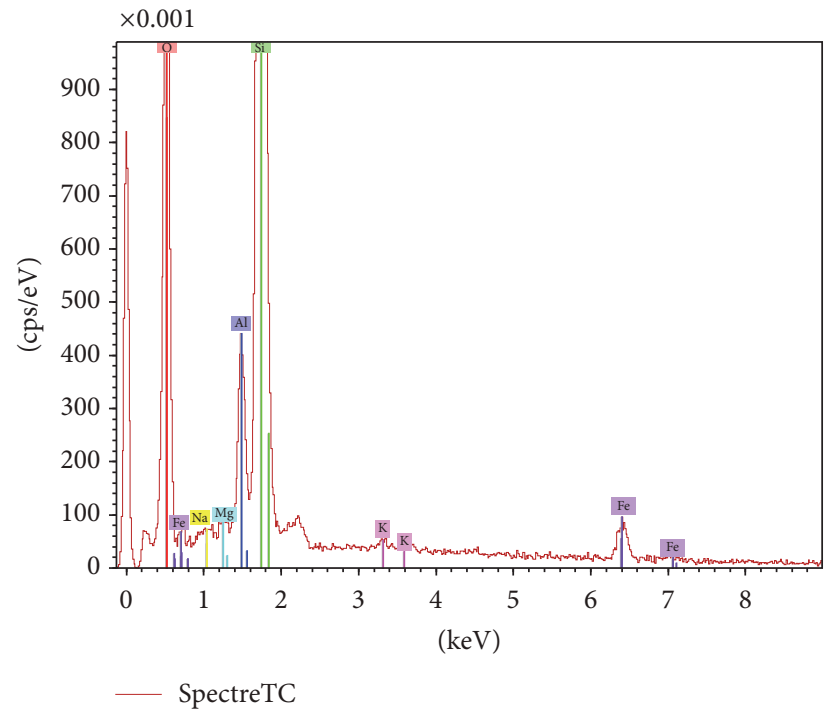

FIGURE 3: EDAX spectrum of the fired clay pots.

attributed to competition between hydroxide and fluoride ion having the same charge and similar radius [32]. The maximum adsorption was obtained at the $\mathrm{pH} 5$. The obtained result for maximum adsorption is in agreement with fluoride removal studies on red mud $(\mathrm{pH} 5.5)$ [20], refractory grade bauxite ( $\mathrm{pH}$ 5.5) [33]. Adsorption is also not favored in the acid range; this may be a result of the formation of weakly ionized hydrofluoric acid [20].

The pseudo-first-order, pseudo-second-order, and intraparticle diffusion models were used to test the adsorption kinetics data to investigate the mechanism of adsorption. The pseudo-first-order rate expression of Lagergren is given as [34]

$$
\log \left(q_{e}-q_{t}\right)=\log q_{e}-\frac{k_{1}}{2,303} t
$$

where $q_{t}(\mathrm{mg} / \mathrm{g})$ is the amount of adsorbed fluoride at time $t, k_{1}\left(\mathrm{~min}^{-1}\right)$ is the rate constant of the first-order reaction, and $q_{e}$ is the equilibrium sorption uptake derived from extrapolation of experimental data at time $t=$ infinity. A straight line of $\log \left(q_{e}-q_{t}\right)$ versus $t$ suggests the applicability of this kinetic model (Figure 5(a)). $q_{e}$ and $k_{1}$ (Table 2)

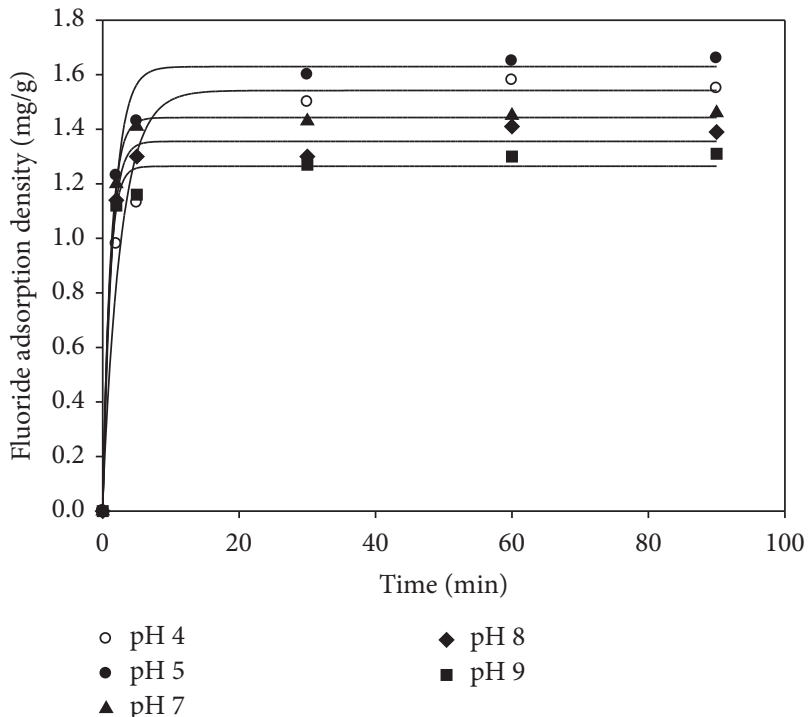

FIgURE 4: Adsorption kinetics at different $\mathrm{pH}$ (stirring speed $120 \mathrm{rpm}$; initial fluoride concentration $=10 \mathrm{mg} / \mathrm{L}$; adsorbent dose $=$ $\left.1 \mathrm{~g} / \mathrm{L}, T=25 \pm 2^{\circ} \mathrm{C}\right)$.

were determined from the intercept and slope of the plot, respectively.

The pseudo-second-order kinetic model [34] is integrated and linearized form has been used:

$$
\frac{t}{q_{t}}=\frac{1}{k_{2} q_{e}^{2}}+\frac{1}{q_{e}} t .
$$

The plot of $t / q_{t}$ versus $t$ (Figure 5(b)) gave a straight line showing that second-order kinetic model was applicable and $q_{t}$ and $k_{2}$ (Table 2) were determined from the slope and intercept of the plot, respectively.

From Table 2, the values of correlation coefficients obtained for the pseudo-first-order reaction were not appropriate to describe the adsorption of fluoride on fired clay. On the contrary, the values of correlation coefficients for pseudo-second-order model were all greater than 0.95 and the adsorption capacities calculated by the model are close to those determined by experiments. Hence, the data was well correlated by the pseudo-second-order model as shown in Figure 5. This fact suggested that the rate of fluoride 
TABLE 2: Kinetics parameters for adsorption of fluoride on fired clay.

\begin{tabular}{|c|c|c|c|c|c|c|c|c|c|}
\hline \multirow[b]{2}{*}{$\begin{array}{l}\text { Initial concentration } \\
(\mathrm{mg} / \mathrm{L})\end{array}$} & \multicolumn{4}{|c|}{ First-order model } & \multicolumn{3}{|c|}{ Second-order model } & \multicolumn{2}{|c|}{ Intraparticle diffusion model } \\
\hline & $\begin{array}{l}q_{e, \exp } \\
(\mathrm{mg} / \mathrm{g})\end{array}$ & $\begin{array}{c}k_{1} \\
\left(\min ^{-1}\right)\end{array}$ & $\begin{array}{c}q_{e, \mathrm{cal}} \\
(\mathrm{mg} / \mathrm{g})\end{array}$ & $R^{2}$ & $\begin{array}{c}k_{2} \\
\left(\mathrm{~g} \cdot \mathrm{mg}^{-1} \mathrm{~min}^{-1}\right)\end{array}$ & $\begin{array}{c}q_{e, \mathrm{cal}} \\
(\mathrm{mg} / \mathrm{g})\end{array}$ & $R^{2}$ & $\begin{array}{c}k_{p} \\
\left(\mathrm{mg} \cdot \mathrm{g}^{-1} \cdot \min ^{-0.5}\right)\end{array}$ & $R^{2}$ \\
\hline 10 & 1.40 & 0.25 & 0.87 & 0.87 & 0.48 & 1.30 & 0.97 & 0.45 & 0.99 \\
\hline 40 & 2.17 & 0.49 & 0.90 & 0.90 & 0.28 & 2.06 & 0.98 & 0.73 & 0.98 \\
\hline
\end{tabular}

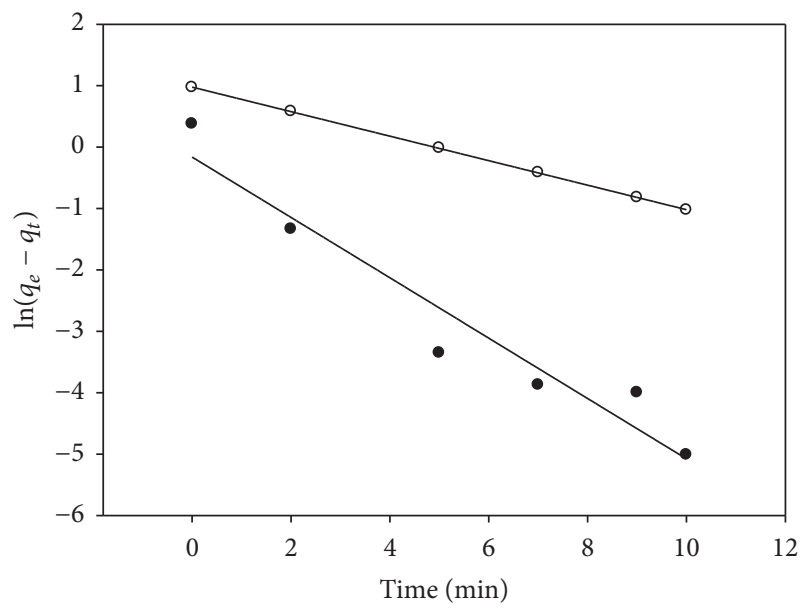

- $10 \mathrm{mg} / \mathrm{L}$

- $40 \mathrm{mg} / \mathrm{L}$

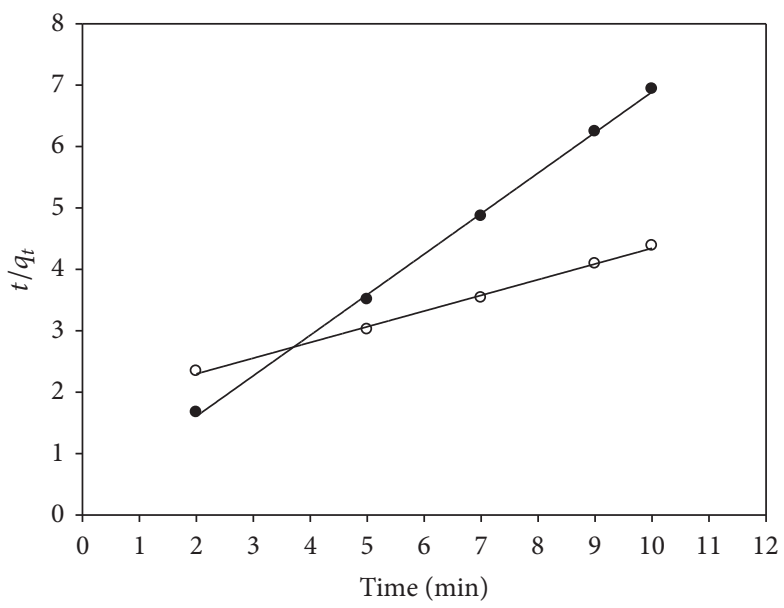

- $10 \mathrm{mg} / \mathrm{L}$

- $40 \mathrm{mg} / \mathrm{L}$

(a)

(b)

FIGURE 5: First-order (a) and second-order kinetics modeling of fluoride adsorption on fired clay pots (adsorbent dose $1 \mathrm{~g} / \mathrm{L}$, $\mathrm{pH}=7$, and temperature $25 \pm 2^{\circ} \mathrm{C}$ ).

adsorption onto fired clay is dependent on the availability of adsorption sites rather than the adsorbate concentration in solution [35].

To evaluate the limiting rate of the fluoride adsorption on fired clay, the possible contribution of intraparticle diffusion on fluoride adsorption process was explored using WeberMorris model [36]:

$$
q=k_{\mathrm{int}} t^{0,5}+C
$$

where $k_{\text {int }}$ can be calculated from the slope of the plot of $q$ versus $t^{1 / 2}$. As shown in Figure 6(a), the linear portion of plot is not passing through the origin at each of the tested concentrations, which indicates the fluoride adsorption on fired clay is a complex procedure. Both the surface adsorption as well as intraparticle diffusion contributes to the rate determining step $[16,37]$.

The data was further used to investigate the slow step occurring in the present adsorption system. The applicability of Bahangam's equation [38] was tested

$$
\log \log \left(\frac{C_{0}}{C_{0}-q m}\right)=\log \left(\frac{k_{0} m}{2,303 V}\right)+\alpha \log t,
$$

where $C_{0}$ is the initial concentration of the adsorbate in solution $(\mathrm{mg} / \mathrm{L}), V$ is the volume of the solution $(\mathrm{L}), m$ is the weight of adsorbent used per liter of solution, $q$ is the amount of adsorbate retained at time $t$, and $\alpha(<1)$ and $k_{0}$ are constants to the present system which was examined. As such, $\log \log \left(C_{0} /\left(C_{0}-q m\right)\right)$ was plotted against $\log t$ in Figure 6(b). The plot was found to be linear and the correlation coefficients are greater than 0.95 indicating that kinetics confirms Bahangam's equation and therefore the adsorption of fluoride on fired clay was pore diffusion controlled [37].

3.3. Adsorption Isotherms. Fluoride ion adsorption was carried out at $\mathrm{pH} 4$ and stirring speed of $120 \mathrm{rpm}$. Two isotherms equations have been applied for this study, Langmuir and Freundlich. The linear form of the Langmuir equation is given by

$$
\frac{C_{e}}{q_{e}}=\frac{C_{e}}{Q_{m}}+\frac{1}{Q_{m} b},
$$

where $q_{e}$ and $C_{e}$ are the equilibrium concentrations of fluoride in the adsorbed $(\mathrm{mg} / \mathrm{g})$ and liquid phases $(\mathrm{mg} / \mathrm{L})$, respectively. $Q_{m}$ and $b$ are the Langmuir constants which are related to the adsorption capacity and energy of adsorption, respectively, and can be calculated from the intercept and slope of the linear plot, with $C_{e} / q_{e}$ versus $C_{e}$.

The adsorption equilibrium data was also applied to Freundlich isotherm model. The linear form of the model can be expressed as follows:

$$
\log q_{e}=\log k_{F}+\frac{1}{n} \log C_{e},
$$




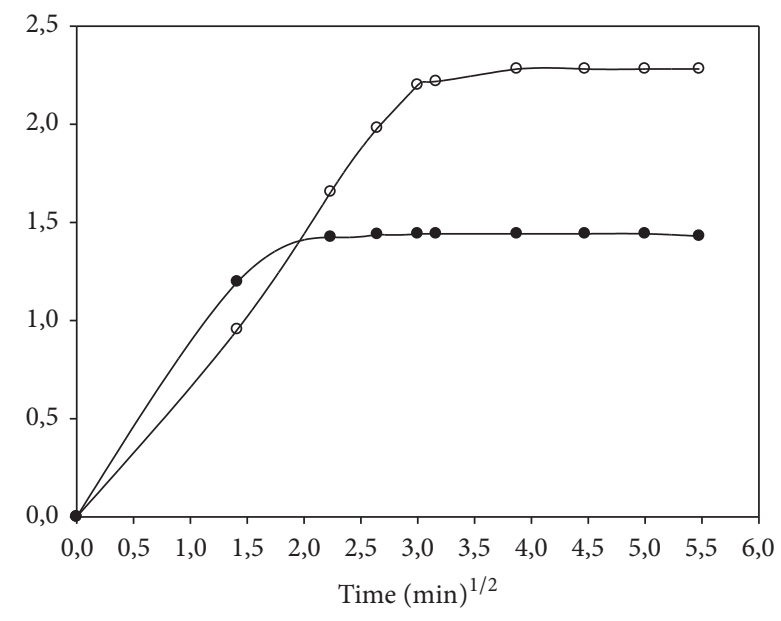

- $10 \mathrm{mg} / \mathrm{L}$

○ $40 \mathrm{mg} / \mathrm{L}$

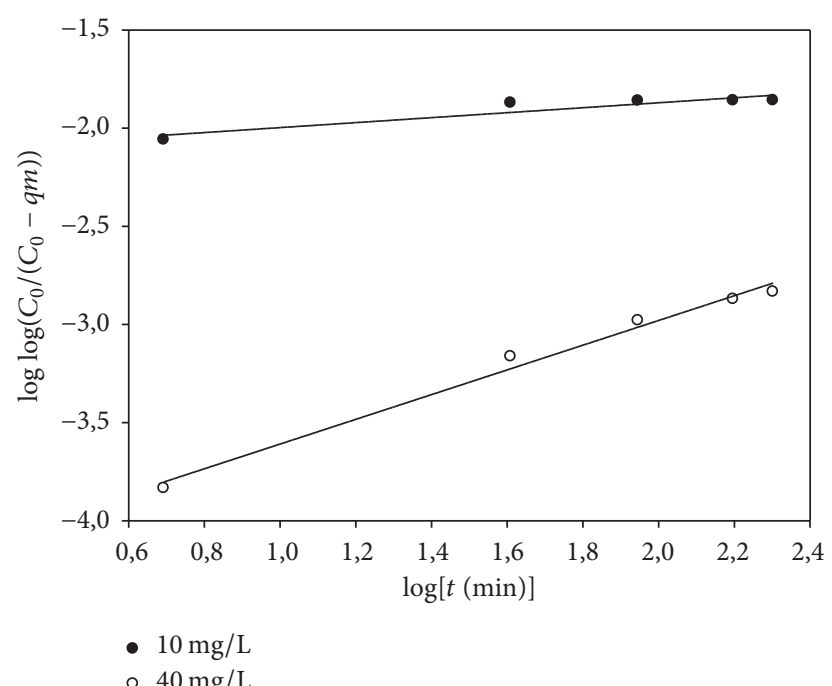

(b)

FIGURE 6: Intraparticle diffusion model (a) and Bahangam's equation plot (b) (adsorbent dose $1 \mathrm{~g} / \mathrm{L}, \mathrm{pH}=7$, and temperature $25 \pm 2^{\circ} \mathrm{C}$ ).

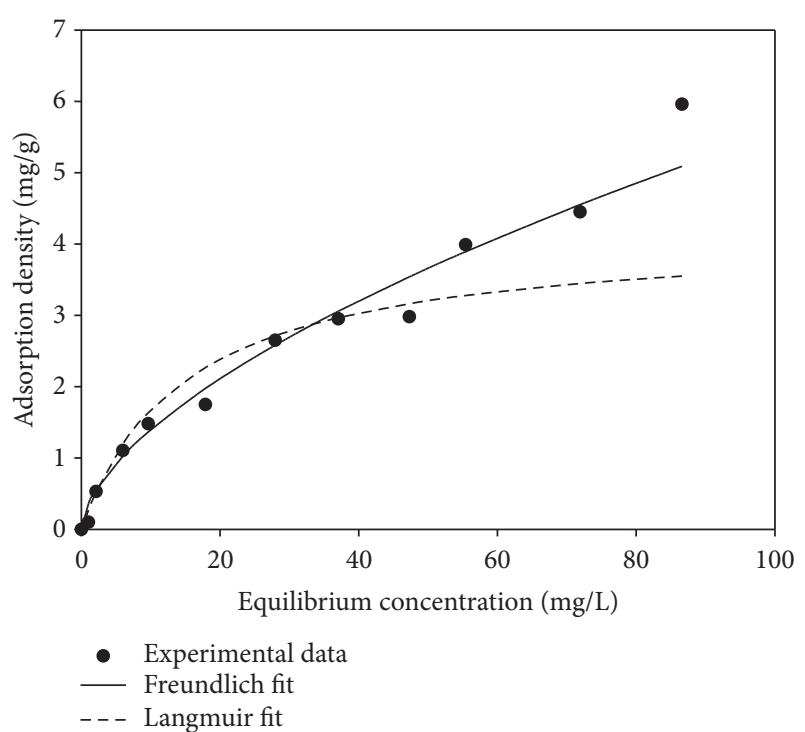

FIGURE 7: Adsorption isotherms of fluoride on fired clay pots (stirring speed $120 \mathrm{rpm} ; \mathrm{pH}=4$; contact time $=30 \mathrm{~min}$ ).

where $q_{e}$ and $C_{e}$ are the equilibrium concentration of fluoride in the adsorbed $(\mathrm{mg} / \mathrm{g})$ and liquid phases $(\mathrm{mg} / \mathrm{L})$, respectively. $k_{F}$ and $n$ are the Freundlich constants which are related to adsorption capacity and intensity, respectively. These constants can be calculated from the slope and intercept of the linear plot, with $\log q_{e}$ versus $\log C_{e}$.

To show the ability of different isotherms to correlate with experimental results, the theoretical plots from each isotherm have been fitted with the experimental data for adsorption of fluoride on fired clay pots (Figure 7). Langmuir and Freundlich parameters and regression coefficients $\left(R^{2}\right)$ are presented in Table 3. From Figure 7, the adsorption data fitted well with Freundlich isotherm model indicating
TABLE 3: Langmuir and Freundlich isotherms parameters for the adsorption of fluoride on fired clay pots.

\begin{tabular}{lccc}
\hline Models & \multicolumn{3}{c}{ Parameters } \\
\hline \multirow{2}{*}{ Langmuir } & $b\left(\mathrm{~L} \cdot \mathrm{mg}^{-1}\right)$ & $q_{\max }(\mathrm{mg} / \mathrm{g})$ & $R^{2}$ \\
& 0.067 & 4.16 & 0.95 \\
\hline \multirow{2}{*}{ Freundlich } & $k_{f}(\mathrm{mg} / \mathrm{g})$ & $n$ & $R^{2}$ \\
& 0.35 & 0.602 & 0.98 \\
\hline
\end{tabular}

the heterogeneous distribution of active sites on fired clay pot [39]. The value of the correlation coefficient is 0.98 , indicating a good mathematical fit. The Langmuir plot model has lower $R^{2}$ than the Freundlich model. In order to predict the adsorption efficiency of the adsorption process, the dimensionless equilibrium parameters were determined by using the following equation:

$$
R=\frac{1}{1+b C_{0}}
$$

where $C_{0}$ is the initial concentration and $b$ is the Langmuir isotherm constant.

The value of $R$ varied from 0.93 to 0.19 . These values are less than 1 , indicating the favorable adsorption of fluoride on fired clay [16].

3.4. Effect Stirring Speed. Effects of stirring speed on the adsorption of fluoride are presented in Figure 8. It is clear from the figure that the adsorption density increases with agitation speed up to $120 \mathrm{rpm}$ and beyond this it is almost constant. The external mass transfer increases with the agitation speed, resulting in an increase in fluoride transport from the bulk to the adsorbent sites and thereby increasing the rate of adsorption. Fluoride adsorption density is almost invariant beyond $120 \mathrm{rpm}$, as the external mass transfer 


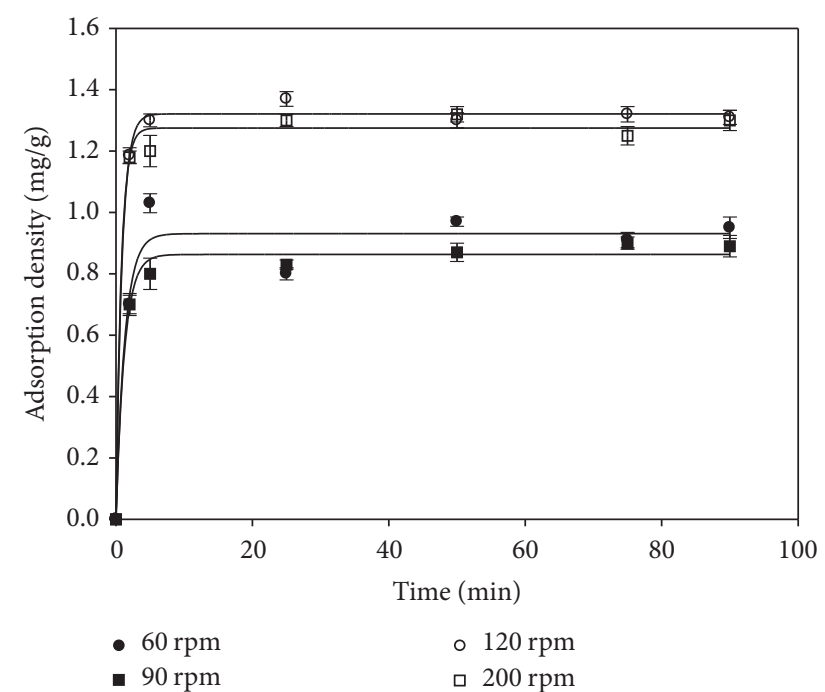

FIGURE 8: Effect of stirring speed on adsorption density of fluoride on fired clay pot powder $(\mathrm{pH}=4$; initial fluoride concentration = $10 \mathrm{mg} / \mathrm{L})$.

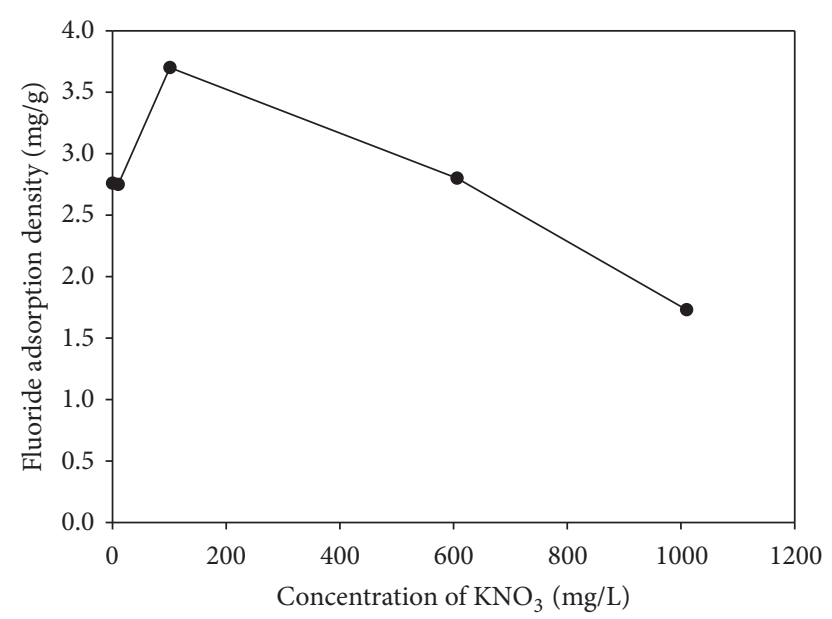

FIGURE 9: Effect of ionic strength $\left(\mathrm{KNO}_{3}\right.$ salt $)$ on adsorption density of fluoride on clay pots powder $(\mathrm{pH}=4$, initial fluoride concentration $=20 \mathrm{mg} / \mathrm{L}$, and contact time $=20 \mathrm{~min}$ ).

resistance does not decrease appreciably beyond this rpm. Therefore, it was suggested that $120 \mathrm{rpm}$ could be suitable for fluoride adsorption by fired clay and no reduction of fluoride retention was observed as found by Ndi et al. [22].

3.5. Effect of Ionic Strength. The effect of ionic strength on fluoride adsorption was studied by varying the concentration of $\mathrm{KNO}_{3}(0-1000 \mathrm{mg} / \mathrm{L})$ (Figure 9). The result showed that the amount of fluoride adsorbed on fired clay pot was significantly affected when the concentration increases from 0 to $1000 \mathrm{mg} / \mathrm{L} \mathrm{KNO}_{3}$. The same effect of ionic strength was also observed for the adsorption of $\mathrm{Cr}(\mathrm{VI})$ on bentonite [40]. Studying the influence of ionic strength is a simple approach to distinguish between inner sphere and outer sphere surface complexes when direct evidence from microscopic data is absent. According to Hayes et al. [41], if the adsorption is not affected by the variations of the ionic strength, then an inner sphere surface complexation should form, whereas the presence of outer sphere complexes is indicated by changes in adsorption with changing ionic strength. Based on this theory, it is postulated that the adsorption of fluoride on fired clay pots may take place by the formation of outer sphere complexation.

\section{Conclusion}

Adsorption of fluoride onto fired clay pots from Cameroon has been studied in detail. Fired clay is composed of different oxides. Kinetic studies reveal that equilibrium is attained within $10 \mathrm{~min}$ whatever the $\mathrm{pH}$ studied. The maximum adsorbed fluoride is $1.3 \mathrm{mg} / \mathrm{g}$ at a stirring speed of $120 \mathrm{rpm}$. Adsorption follows pseudo-second-order and both the surface adsorption and intraparticle diffusion contribute to the rate determining step. Freundlich isotherm fits the adsorption data adequately. The effect of ionic strength has a significant effect on fluoride adsorption.

Being a useless and abundantly available material, fired clay pots can be used for industrial application for removing fluoride from water.

\section{Conflicts of Interest}

The authors declare that they have no conflicts of interest.

\section{References}

[1] W. Y. Fantong, H. Satake, S. N. Ayonghe et al., "Geochemical provenance and spatial distribution of fluoride in groundwater of Mayo Tsanaga River Basin, Far North Region, Cameroon: implications for incidence of fluorosis and optimal consumption dose," Environmental Geochemistry and Health, vol. 32, no. 2, pp. 147-163, 2010.

[2] C. Neal, M. Neal, H. Davies, and J. Smith, "Fluoride in UK rivers," Science of the Total Environment, vol. 314-316, pp. 209231, 2003.

[3] R. Tekle-Haimanot, Z. Melaku, H. Kloos et al., "The geographic distribution of fluoride in surface and groundwater in Ethiopia with an emphasis on the Rift Valley," Science of the Total Environment, vol. 367, no. 1, pp. 182-190, 2006.

[4] WHO (World Health Organization, Guidelines for Drinking Water Quality), World Health Organization, Geneva, 2006.

[5] Meenakshi and R. C. Maheshwari, "Fluoride in drinking water and its removal," Journal of Hazardous Materials, vol. 137, no. 1, pp. 456-463, 2006.

[6] H. Lounici, L. Addour, D. Belhocine et al., "Study of a new technique for fluoride removal from water," Desalination, vol. 114, no. 3, pp. 241-251, 1997.

[7] K. Vaaramaa and J. Lehto, "Removal of metals and anions from drinking water by ion exchange," Desalination, vol. 155, no. 2, pp. 157-170, 2003.

[8] M. S. Onyango and H. Matsuda, "Fluoride removal from water using adsorption technique," Advances in Fluorine Science, vol. 2, pp. 1-48, 2006.

[9] M. Tahaikt, R. El Habbani, A. Ait Haddou et al., "Fluoride removal from groundwater by nanofiltration," Desalination, vol. 212, no. 1-3, pp. 46-53, 2007. 
[10] M. A. M. Sahli, S. Annouar, M. Tahaikt, M. Mountadar, A. Soufiane, and A. Elmidaoui, "Fluoride removal for underground brackish water by adsorption on the natural chitosan and by electrodialysis," Desalination, vol. 212, no. 1-3, pp. 37-45, 2007.

[11] E. Ergun, T. Ali, C. Yunus, and K. Izzet, "Electrodialytic removal of fluoride from water: Effects of process parameters and accompanying anions," Separation and Purification Technology, vol. 64, no. 2, pp. 147-153, 2008.

[12] E. J. Reardon and Y. Wang, "A limestone reactor for fluoride removal from wastewaters," Environmental Science \& Technology, vol. 34, no. 15, pp. 3247-3253, 2000.

[13] T. N. De Castro Dantas, A. A. D. Neto, and M. C. P. De A. Moura, "Removal of chromium from aqueous solutions by diatomite treated with microemulsion," Water Research, vol. 35, no. 9, pp. 2219-2224, 2001.

[14] K. Y. Foo and B. H. Hameed, "Insights into the modeling of adsorption isotherm systems," Chemical Engineering Journal, vol. 156, no. 1, pp. 2-10, 2010.

[15] S. Ghorai and K. K. Pant, "Equilibrium, kinetics and breakthrough studies for adsorption of fluoride on activated alumina," Separation and Purification Technology, vol. 42, no. 3, pp. 265-271, 2005.

[16] M. Mahramanlioglu, I. Kizilcikli, and I. O. Bicer, "Adsorption of fluoride from aqueous solution by acid treated spent bleaching earth," Journal of Fluorine Chemistry, vol. 115, no. 1, pp. 41-47, 2002.

[17] E. Kumar, A. Bhatnagar, M. Ji et al., "Defluoridation from aqueous solutions by granular ferric hydroxide (GFH)," Water Research, vol. 46, pp. 1-9, 2008.

[18] D. Nigamananda, P. Pragyan, and R. Rita, "Defluoridation of drinking water using activated titanium rich bauxite," Journal of Colloid and Interface Science, vol. 292, no. 1, pp. 1-10, 2005.

[19] R. S. Sathish, N. S. R. Raju, G. S. Raju, G. N. Rao, K. A. Kumar, and C. Janardhana, "Equilibrium and kinetic studies for fluoride adsorption from water on zirconium impregnated coconut shell carbon," Separation Science and Technology, vol. 42, no. 4, pp. 769-788, 2007.

[20] Y. Çengeloğlu, E. Kir, and M. Ersöz, "Removal of fluoride from aqueous solution by using red mud," Separation and Purification Technology, vol. 28, no. 1, pp. 81-86, 2002.

[21] P. P. Coetzee, L. L. Coetzee, R. Puka, and S. Mubenga, "Characterisation of selected South African clays for defluoridation of natural waters," Water SA, vol. 29, no. 3, pp. 331-338, 2003.

[22] K. Ndi, G. Kofa, T. Metiotsop, and G. Kayem, "Removal of excess Fluoride from water using Laterite and Kaolinite," in Proceedings of the Conférence de Société Française de Génie des Procédés, Marseille, France, Octobre, 2009.

[23] F. Bergaya and G. Lagaly, "General introduction: clays, clay minerals, and clay science," Developments in Clay Science, vol. 5, pp. 1-19, 2013.

[24] G. Crini, "Non-conventional low-cost adsorbents for dye removal: a review," Bioresource Technology, vol. 97, no. 9, pp. 1061-1085, 2006.

[25] R. Srinivasan, "Advances in application of natural clay and its composites in removal of biological, organic, and inorganic contaminants from drinking water," Advances in Materials Science and Engineering, vol. 2011, Article ID 872531, 17 pages, 2011.

[26] A. Bhatnagar, E. Kumar, and M. Sillanpää, "Fluoride removal from water by adsorption-a review," Chemical Engineering Journal, vol. 171, no. 3, pp. 811-840, 2011.
[27] A. Maiti, J. K. Basu, and S. De, "Chemical treated laterite as promising fluoride adsorbent for aqueous system and kinetic modeling," Desalination, vol. 265, no. 1-3, pp. 28-36, 2011.

[28] Y. Ma, F. Shi, X. Zheng, J. Ma, and C. Gao, "Removal of fluoride from aqueous solution using granular acid-treated bentonite (GHB): batch and column studies," Journal of Hazardous Materials, vol. 185, no. 2-3, pp. 1073-1080, 2011.

[29] J. Osei, S. K. Gawu, A. I. Schäfer, F. A. Atipoka, and F. W. Momade, "Impact of laterite characteristics on fluoride removal from water," Journal of Chemical Technology and Biotechnology, vol. 91, no. 4, pp. 911-920, 2016.

[30] C.-H. Weng, C.-Z. Tsai, S.-H. Chu, and Y. C. Sharma, "Adsorption characteristics of copper(II) onto spent activated clay," Separation and Purification Technology, vol. 54, no. 2, pp. 187197, 2007.

[31] B. Najet, K. Lassine, K. Atsushi et al., "Electrochemical analysis of endocrine disrupting chemicals over carbon electrode modified with cameroon's clay," Journal of the Electrochemical Society, vol. 162, no. 1, pp. B1-B8, 2015.

[32] A. Vinati, B. Mahanty, and S. K. Behera, "Clay and clay minerals for fluoride removal from water: a state-of-the-art review," Applied Clay Science, vol. 114, pp. 340-348, 2015.

[33] D. Mohapatra, D. Mishra, S. P. Mishra, G. Roy Chaudhury, and R. P. Das, "Use of oxide minerals to abate fluoride from water," Journal of Colloid and Interface Science, vol. 275, no. 2, pp. 355359, 2004.

[34] Y. S. Ho and McKay, "The adsorption of lead (II) ion on peat. Reponse to comment," Water Research, vol. 33, pp. 578-584, 1999.

[35] X. Song, Y. Zhang, C. Yan, W. Jiang, and C. Chang, "The Langmuir monolayer adsorption model of organic matter into effective pores in activated carbon," Journal of Colloid and Interface Science, vol. 389, no. 1, pp. 213-219, 2013.

[36] W. J. Weber Jr and J. C. Morris, "Kinetics of adsorption on carbon from solution," Journal of the Sanitary Engineering Division, vol. 40, pp. 31-60, 1963.

[37] V. K. Gupta, I. Ali, and V. K. Saini, "Defluoridation of wastewaters using waste carbon slurry," Water Research, vol. 41, no. 15, pp. 3307-3316, 2007.

[38] C. Aharoni and M. Ungarish, "Kinetics of activated chemisorption. Part 2. Theoretical models," Journal of the Chemical Society, vol. 73, no. 3, pp. 456-464, 1977.

[39] A. Ramesh, H. Hasegawa, T. Maki, and K. Ueda, "Adsorption of inorganic and organic arsenic from aqueous solutions by polymeric $\mathrm{Al} / \mathrm{Fe}$ modified montmorillonite," Separation and Purification Technology, vol. 56, no. 1, pp. 90-100, 2007.

[40] W. Li, Z. Meng, Z. Liu, H. Chen, Q. Wu, and S. Xu, "Chromium (VI) characteristics of bentonite under different modification patterns," Polish Journal of Environmental Studies, vol. 25, no. 3, pp. 1075-1083, 2016.

[41] K. F. Hayes, C. Papelis, and J. O. Leckie, "Modeling ionic strength effects on anion adsorption at hydrous oxide/solution interfaces," Journal of Colloid and Interface Science, vol. 125, no. 2, pp. 717-726, 1988. 

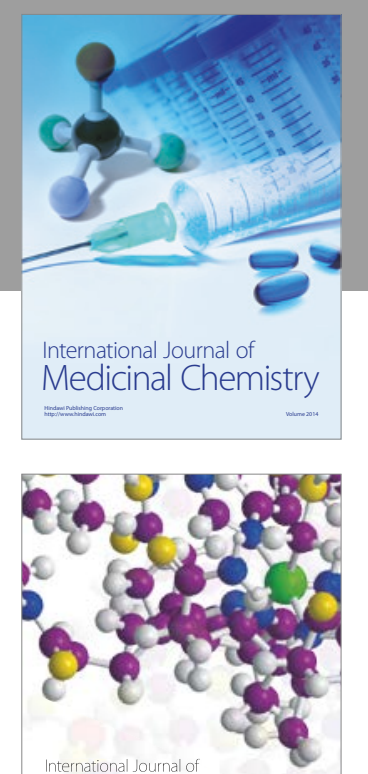

Carbohydrate Chemistry

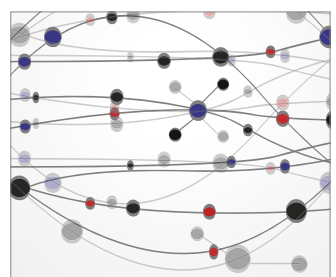

The Scientific World Journal
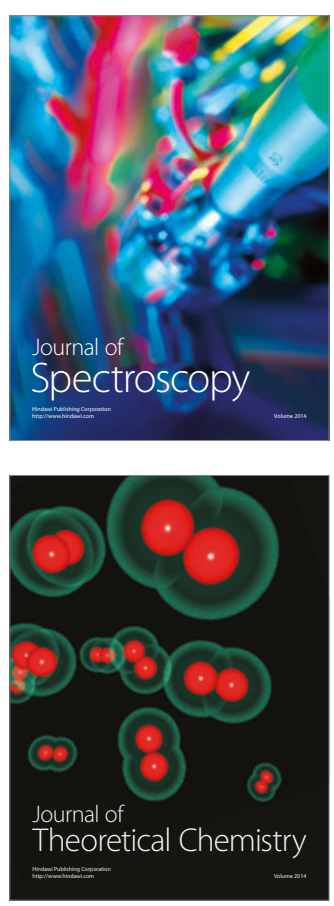
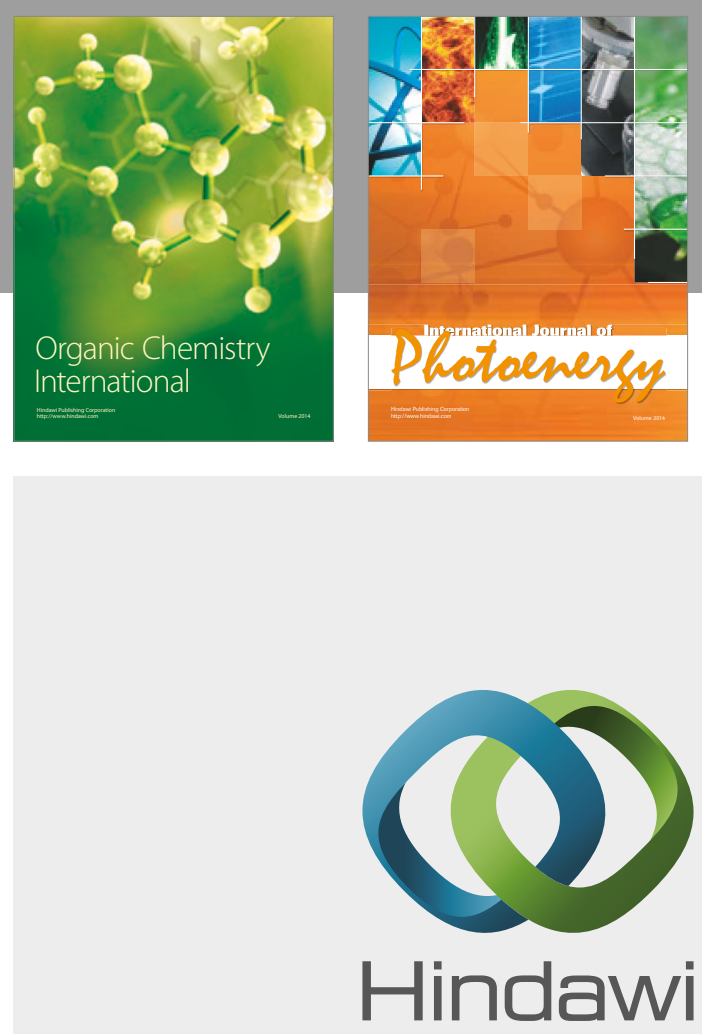

Submit your manuscripts at

https://www.hindawi.com

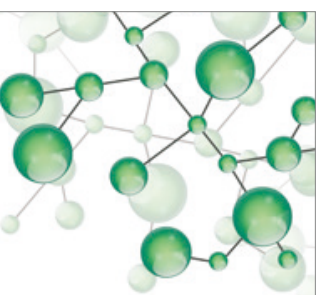

International Journal of

Inorganic Chemistry

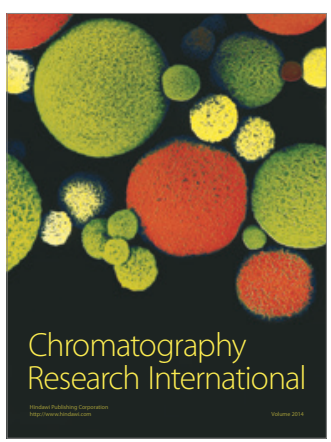

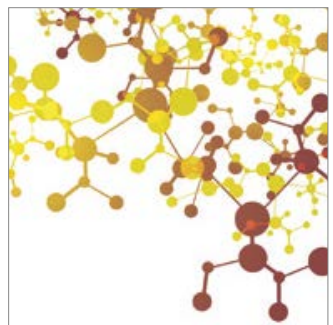

Applied Chemistry
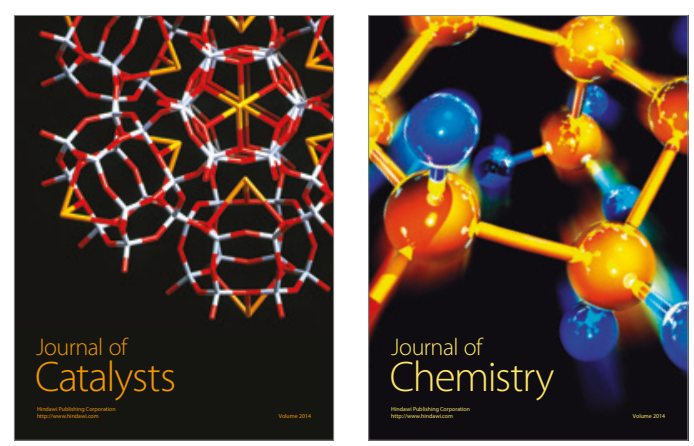
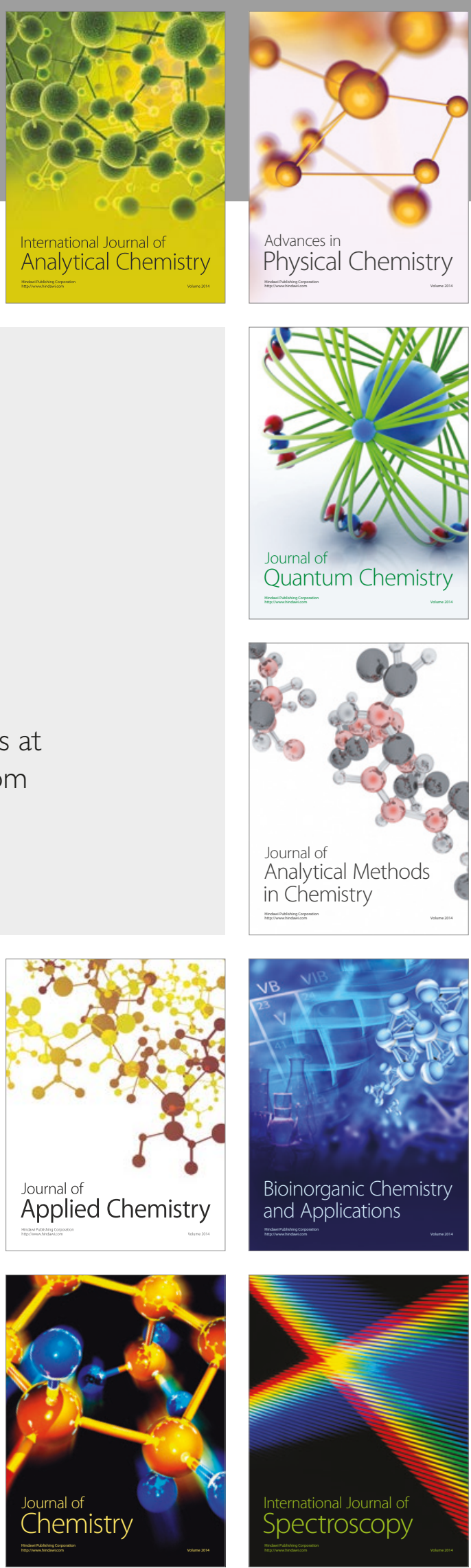